\title{
EFFECT OF ENVIRONMENTAL CONDITIONS UPON TYROSINASE ACTIVITY IN GLOMERELLA CINGULATA ${ }^{1}$
}

\author{
Alfred S. Sussman, ${ }^{2}$ Patricia Coughey, and James C. Strain
}

Previous EXPERIMENTs with Glomerella cingulata have established that tyrosinase activity first appears in plate culture about $120 \mathrm{hr}$. after inoculation and that its formation is probably adaptive in nature (Sussman and Markert, 1953). On the other hand, cytochrome oxidase activity is present at all times in the organism and in roughly equivalent quantities. In an earlier investigation (Markert, 1950) it was noted that the amount of tyrosinase in the mycelium of Glomerella varies with the conditions of nutrition, aeration, and temperature under which the mycelium is grown. More recently, other workers have called attention to the importance of temperature (Horowitz and Shen, 1952) in the formation of tyrosinase in Neurospora, and in the formation of other fungous enzymes (Fries, 1953). The following experiments were designed, therefore, to explore the effects of these factors and others upon tyrosinase formation in Glomerella.

METHODS.-The organism used in these experiments was the standard type $\left(\mathrm{A}^{1} \mathrm{~B}^{1}\right)$ of Glomerella cingulata which is a conidiating double mutant from the wild type. Surface cultures were grown from mass conidial inoculum, usually on $30 \mathrm{ml}$. of agar medium in Petri dishes, and incubated at $20^{\circ} \mathrm{C}$. until harvested. Where divergence from these techniques occurred, mention will be made before the results are presented. The "complete" Neurospora medium (Ryan, 1950) was used, except where otherwise noted.

Mycelia were harvested and handled as described by Sussman and Markert (1953). Enzyme extracts were made by grinding the weighed mycelial mats in $1 / 15 \mathrm{M}$ phosphate buffer at $\mathrm{pH} 7.2$ with a glass homogenizer. The "brei" was centrifuged at 100 $X \mathrm{~g}$ for $15 \mathrm{~min}$. after which the supernatant fluid was collected and used.

Tyrosinase activity was determined colorimetrically by the method of Markert (1950) as modified (Sussman and Markert, 1953) to employ a Beckman spectrophotometer. In this investigation the model DU was used in place of the model B. The reaction mixture consisted of $1 \mathrm{ml}$. of $0.02 \mathrm{M}$ DL-dihydroxyphenylalanine (dopa), $0.1 \mathrm{ml}$. of the enzyme preparation, and $1.5 \mathrm{ml}$ of $1 / 15 \mathrm{M}$ phosphate buffer at $\mathrm{pH} 6.5$. In certain instances, less enzyme was used because of the preparation's high activity; when this was done, enough buffer was added to bring the total volume to $3.0 \mathrm{ml}$. The substrate was added at zero time and readings were made at $480 \mathrm{~m} \mu$ at 10 -sec. intervals. The change in

1 Received for publication January 24, 1955.

2 This work was made possible by a grant from the Committee on Growth of the American Cancer Society. optical density during this time was used in computing tyrosinase activity. Previously (Sussman and Markert, 1953), check runs with this material using manometric techniques had established that no reducing substances were interfering with the determinations by preventing color formation. Also it was assumed that no endogenous inhibitor of the enzyme, such as is present in Neurospora, can be found in Glomerella since the several inactive preparations checked by the methods of Horowitz and Shen (1953) showed no such substance.

The enzyme extracts were standardized on the basis of their total nitrogen content. These determinations were made by means of a direct nesslerization after sulfuric acid and peroxide digestion, according to a modification of the meihod of Koch and McMeekin (1924). The average weight of two mycelial mats dried at $105^{\circ} \mathrm{C}$. overnight was used as a measure of the growth of the organism.

In later experiments, the extracts were stancardized on the basis of the mg. protein in the extract. The method used was that of Kalckar (1947) wherein the difference between the extinction of the solution at 280 and $260 \mathrm{~m} \mu$ was computed after the use of constants to correct for the specific absorption of nucleic acids and proteins at these wavelengths. In no case did the nucleic acid content of the enzyme preparations, computed from the ratio of the extinctions at the same wavelengths, exceed 20 per cent.

Results.-Effect of amount of medium upon tyrosinase activity. - Occasional inconsistencies in the time of inception of tyrosinase activity had been noted previously (Sussman and Markert, 1953). In checking back over the techniques used, a likely possibility was that the amount of medium used influenced enzyme formation. In order to investigate this possibility, plates containing $10,20,30$, and $60 \mathrm{ml}$. of complete medium were prepared, inoculated, and incubated as usual. Samples were harvested periodically for enzyme analysis and for dry weight determinations and the results plotted in fig. 1. In order to check whether lack of tyrosinase activity was due to the actual absence of the enzyme or to the presence of an inhibitor in the extracts, dialysis experiments were performed, but no increase in activity resulted. Moreover, the addition of inactive extracts to an active one did not result in any decrease in the expected activity. It is immediately obvious that the amount of medium has effect upon the time of inception and a lesser effect upon the titer of tyrosinase activity. The fact that the maximum titer shows considerable variation is not surprising since it has been shown that 
the peak of tyrosinase activity is rather sharp so that it is easy to miss the peak, unless samples are taken at very short time intervals (Sussman and Markert, 1953). In $10 \mathrm{ml}$. of medium Glomerella forms tyrosinase shortly after $100 \mathrm{hr}$. but when 60 $\mathrm{ml}$. of medium are used, the enzyme is formed only after $220 \mathrm{hr}$. Other experiments were performed which showed that the maximum titer reached in $10,20,30$, and $60 \mathrm{ml}$. of medium was 1300,1430 , 1200 , and 1400 respectively calculated as (opt. dens. $/$ min. $/ 100 \mathrm{~N}) \times 10^{3}$. It seems clear therefore that approximately the same amount of activity is obtained in all cases but that the inception of activity is delayed in the culture grown in larger amounts of media. These data also establish that the cessation of growth coincides with the time of induction of tyrosinase activity, as was previously shown (Sussman and Markert, 1953).

The previous experiments suggested two possibilities: first, that the increased amount of medium permitted more growth and thereby delayed the inception of tyrosinase activity; and second, that the mere increase in the depth of the medium was somehow responsible for the observed differences.

- These possibilities were investigated by the use of doubled and trebled amounts of all the components of the complete medium, except for the agar and water. Thirty ml. of medium were used and the plates were inoculated, incubated, and harvested as before. Although the peak of growth was reached at about $142 \mathrm{hr}$. in the doubled medium, and at about $172 \mathrm{hr}$. in the trebled one, no tyrosinase activity occurred in either case even after as long as $600 \mathrm{hr}$. of incubation.

That no inhibitor of tyrosinase were present as in Neurospora was shown by experiments wherein enzyme preparations from these samples were added to preparations of known activity. Since there was no effect upon the rate of oxidation it was conclud-

TABLE 1. Tyrosinase activity in cultures started at $30^{\circ} \mathrm{C}$. and moved to $20^{\circ} \mathrm{C}$. at various times after the start of incubation

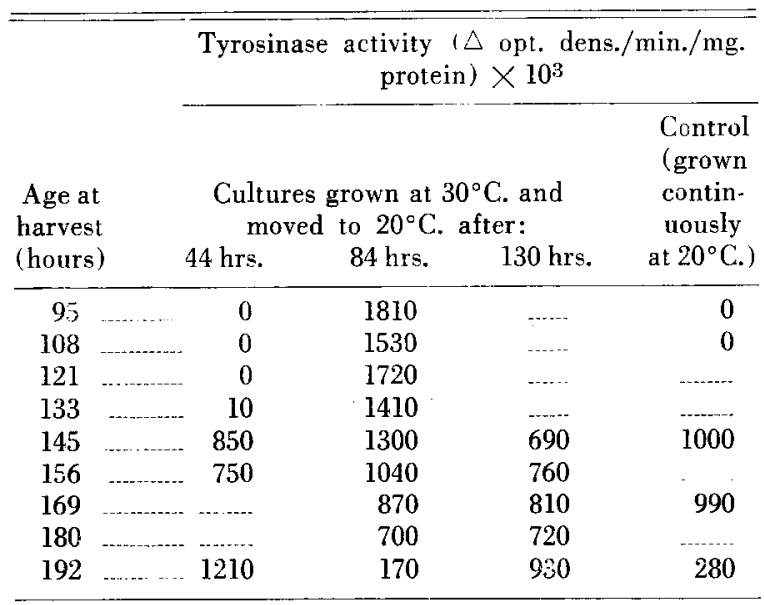

ed that there was no endogenous inhibitor present in Glomerella extracts.

Effect of temperature upon tyrosinase activity.Horowitz and Shen's (1953) results showing that no ty rosinase is produced when Neurospora is grown at $35^{\circ} \mathrm{C}$. was in accord with qualitative observations of the growth of Glomerella (Markert, 1950). Experiments designed to explore this effect disclosed that temperature did indeed have a marked effect upon both the time of inception of enzyme activity and upon the amount. These results are presented in fig. 2. Experiments were also carried out at $33^{\circ} \mathrm{C}$. and $36^{\circ} \mathrm{C}$., but since results were identical with those at $30^{\circ} \mathrm{C}$., only the latter are presented. The maximum enzyme titer decreases progressively with increased temperature. At $30^{\circ} \mathrm{C}$. and above, no tyrosinase is produced at any time during the growth of the organism. This is so despite the fact that there is no inhibition of growth until temperatures above $34^{\circ} \mathrm{C}$. are used. Indeed, the only effect is upon the rate of growth since the maximum is reached at $60 \mathrm{hr}$. instead of at $110 \mathrm{hr}$. as in cultures grown at $20^{\circ} \mathrm{C}$. The decrease in maximum titer is accompanied by earlier appearance of enzyme. For example, measurable activity is obtainable at $109 \mathrm{hr}$. after inoculation in the case of cultures grown at $22-26^{\circ} \mathrm{C}$., but none is obtained until $120 \mathrm{hr}$. at $20^{\circ} \mathrm{C}$.

In order to determine whether the loss of tyrosinase activity at high temperatures was reversible, cultures were grown on complete medium in Petri plates at $30^{\circ}$ and $36^{\circ}$. At various times after the start of incubation, plates were removed and trans. ferred to $20^{\circ} \mathrm{C}$. Plates were harvested after vary. ing times of incubation and tyrosinase activity measured. The results are given in tables 1 and 2 and show that activity was found in all cultures started at $30^{\circ} \mathrm{C}$. and moved to $20^{\circ} \mathrm{C}$. This is so even for cultures kept at $30^{\circ} \mathrm{C}$. until after the logarithmic phase of growth had ceased (about $130 \mathrm{hr}$.). That no decrease in activity, as compared to controls at $20^{\circ} \mathrm{C}$., was occasioned by incubation at $30^{\circ} \mathrm{C}$. is shown for the 44-hr. and the 84-hr. samples. In fact, there appears even to be some increase in such activity, as well as a speeding of the time of inception of this activity. For example, there is high activity in cultures which were harvested at $95 \mathrm{hr}$., after $84 \mathrm{hr}$. of prior incubation at $30^{\circ} \mathrm{C}$. In contrast, the controls showed no significant activity until after $133 \mathrm{hr}$. It should be pointed out that, in this case, activity appeared in inactive cultures after $11 \mathrm{hr}$. at $20^{\circ} \mathrm{C}$.

The situation is somewhat different for those cultures grown at $36^{\circ} \mathrm{C}$. and transferred to $20^{\circ} \mathrm{C}$. If incubation at $36^{\circ}$ is continued beyond $48 \mathrm{hr}$., no tyrosinase is produced after transfer to $20^{\circ}$. However, if cultures are transferred before this time a somewhat reduced amount of activity is obtained. Mycelial transplants were also taken from cultures that had heen grown at $36^{\circ} \mathrm{C}$. for over $200 \mathrm{hr}$. and 

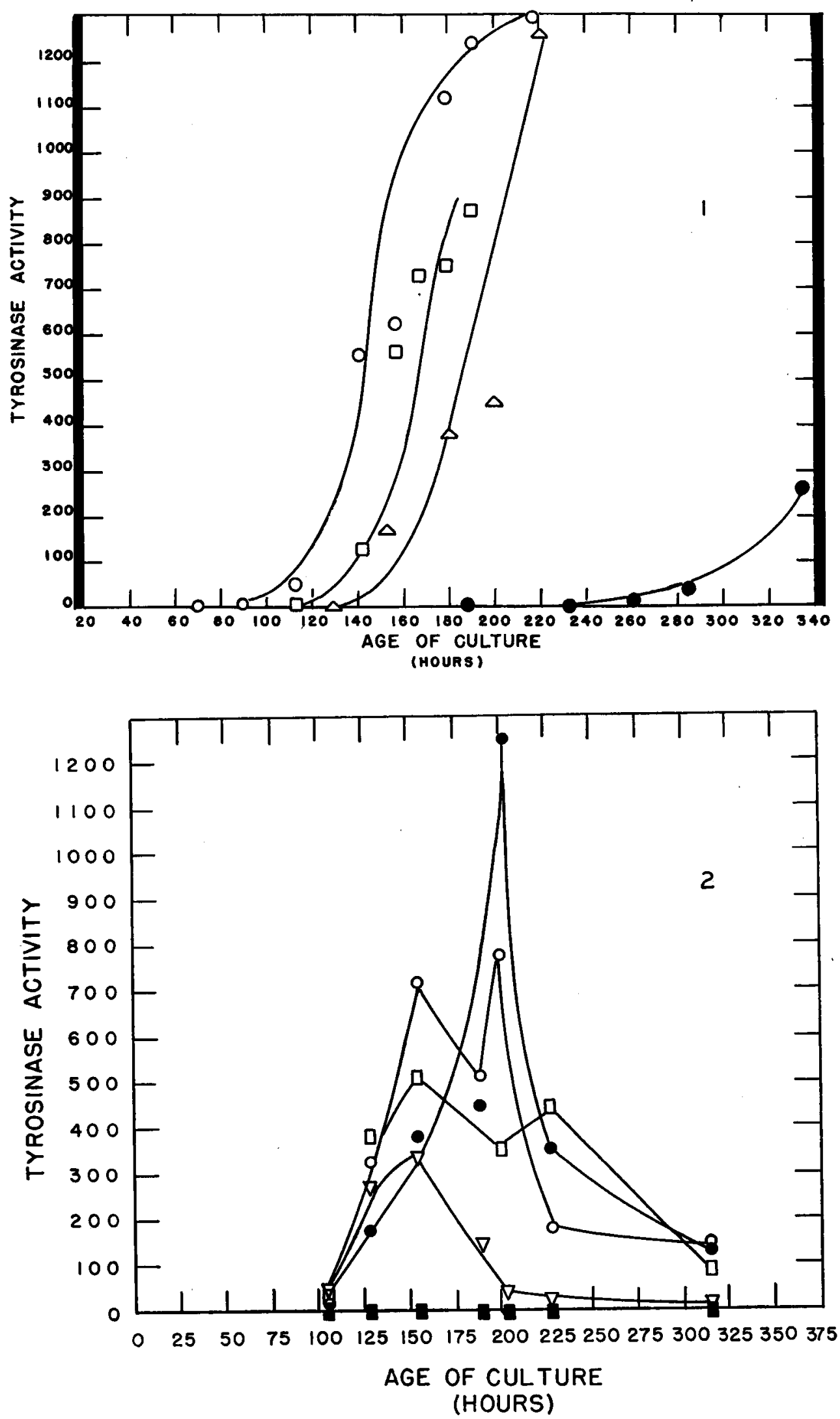
TABLE 2. Tyrosinase activity in cultures started at $36^{\circ} \mathrm{C}$. and moved to $20^{\circ} \mathrm{C}$. at various times after the start of incubation. All cultures were harvested after a total of $212 \mathrm{hr}$. of incubation

\begin{tabular}{cc}
\hline \hline $\begin{array}{c}\text { Hours grown } \\
\text { at } 36^{\circ} \mathrm{C} .\end{array}$ & $\begin{array}{c}\text { Tyrosinase activity }(\triangle \text { opt. } \\
\text { dens./min. } / \text { mg. protein }) \times 10^{3}\end{array}$ \\
\hline 10 & 690 \\
22 & 530 \\
36 & 10 \\
48 & 0 \\
72 & 0 \\
\hline
\end{tabular}

inoculations were made on complete medium. In all instances where the transplants were incubated at $20^{\circ} \mathrm{C}$., tyrosinase activity was obtained. Up to now, therefore, tyrosinase activity has always reappeared in the first generation after heat treatment.

Sussman and Markert (1953) had shown that the inception of tyrosinase activity in the standard type and certain mutants of Glomerella seemed to coincide with the beginning of autolysis. It was suggested, therefore, that high temperatures of incubation might be interfering with the autolytic process and thereby preventing the synthesis of the enzyme. To test this hypothesis, the growth of the standard type on $30 \mathrm{ml}$. of "complete" medium was measured at $20^{\circ}, 30^{\circ}$, and $36^{\circ} \mathrm{C}$. and the results given in table 3 . Although the rate of growth at $30^{\circ} \mathrm{C}$. is faster than that at the other temperatures, no marked difference in the total amount of growth or autolysis was observable.

The question then arose as to whether the failure of the enzyme to appear at $30^{\circ} \mathrm{C}$. was due to the lability of the enzyme itself or to the lability of the agent(s) responsible for its formation. This problem was first approached by exposing duplicate samples of Glomerella tyrosinase, extracted as described previously, to temperatures of 20 and $35^{\circ} \mathrm{C}$. The activity of these preparations was measured at several times after the beginning of incubation but no significant difference between the two samples was apparent as long as $2 \mathrm{hr}$. after incubation was begun. Further experiments to decide this point were carried out by growing the organism at $20^{\circ} \mathrm{C}$. for periods of time long enough to permit the development of tyrosinase activity. After these times, the cultures were transferred to $30^{\circ} \mathrm{C}$. and their tyrosinase activity measured after such incubation. The results of these experiments are given in fig. 3 . What is most evident is that exposure to $30^{\circ}$ causes an immediate decrease in enzyme activity. This is clear in all cases except in those samples transferred to $30^{\circ} \mathrm{C}$. after $120 \mathrm{hr}$. although even here the increase is so small, when compared to the ultimate titer reached at $20^{\circ}$, as to be negligible. Moreover, the fact that no precipitous loss in activity resulted when cultures were transferred after $120 \mathrm{hr}$. suggests that the enzyme, once formed, is relatively thermostable. For example, almost half of the organism's tyrosinase activity after $220 \mathrm{hr}$. is retained during $20 \mathrm{hr}$. of incubation at $30^{\circ}$ and considerable activity still remains after $60 \mathrm{hr}$. of incubation. However, those cultures transferred to $30^{\circ}$ after $120 \mathrm{hr}$. do show a net loss in tyrosinase activity and it is likely that this decrease is associated with a system, normally present in the organism, that destroys the enzyme (see Discussion).

Effect of carbon source upon tyrosinase activity. -The differences in tyrosinase activity obtained by varying physical factors suggested that chemical factors would also influence this activity. For this reason, a start was made toward delineating some of the factors concerned by varying the carbon source. This was accomplished by using different sugars in a concentration of $0.1 \mathrm{M}$ in $25 \mathrm{ml}$. of complete medium. The cultures were grown at $20^{\circ} \mathrm{C}$. and harvested at various times and their tyrosinase activity and growth determined with the results shown in tables 4 and 5 . The dependence of tyrosinase activity upon the type of carbon source is clear from these data since the maximum titers range from 8500 for cultures grown in mannitol to 1 and 2 in those grown in maltose and trehalose. Moreover, activity was manifested in mannitol at a much earlier time than in any of the other sugars. Al.

TABLE 3. Growth of Glomerella cingulata at various temperatures on "complete" medium. The dry weights of duplicate samples were averaged to provide a measure of growth

\begin{tabular}{|c|c|c|c|}
\hline \multirow{2}{*}{$\begin{array}{l}\text { Hours of } \\
\text { growth }\end{array}$} & \multicolumn{3}{|c|}{ Amount of growth (dry wt. in mg.) at: } \\
\hline & $20^{\circ} \mathrm{C}$. & $30^{\circ} \mathrm{C}$. & $36^{\circ} \mathrm{C}$ \\
\hline 54 & 248 & 307 & 222 \\
\hline $66 \ldots$ & 275 & 383 & 260 \\
\hline 78 & 290 & 358 & 245 \\
\hline 89 & 300 & 348 & 331 \\
\hline $102 \ldots$ & 312 & 320 & 288 \\
\hline 114 & 319 & 322 & $\ldots$ \\
\hline 126 & 308 & 315 & 236 \\
\hline 150 & 288 & 269 & 205 \\
\hline 179 & 265 & 237 & 202 \\
\hline 198 & 240 & 238 & 195 \\
\hline 246 & 200 & 203 & 194 \\
\hline 294 & 195 & 231 & $\ldots$ \\
\hline
\end{tabular}

Fig. 1-2.-Fig. 1. Effect of different amounts of medium upon tyrosinase formation in Glomerella. Tyrosinase activity is expressed as ( $\triangle$ optical density $/ \mathrm{min} . / 100 \mathrm{mg} . \mathrm{N}_{2}$ ) $\times 10^{3}$. Legend: open circles, $10 \mathrm{ml}$. of medium; squares, $20 \mathrm{ml}$., triangles, $30 \mathrm{ml}$; closed circles, $60 \mathrm{ml}$.-Fig. 2. Effect of temperature upon tyrosinase formation in Glomerella. Tyrosinase activity is expressed as ( $\triangle$ optical density $\left./ \mathrm{min} . / 100 \mathrm{mg} . \mathrm{N}_{2}\right) \times 10^{3}$. Each plate contained $25 \mathrm{ml}$. of "complete" medium. Legend: closed circles, cultures grown at $20^{\circ}$; open circles, $22^{\circ}$; open squares, $24^{\circ} ;$ triangles, $26^{\circ}$; closed squares, $30^{\circ}$. 


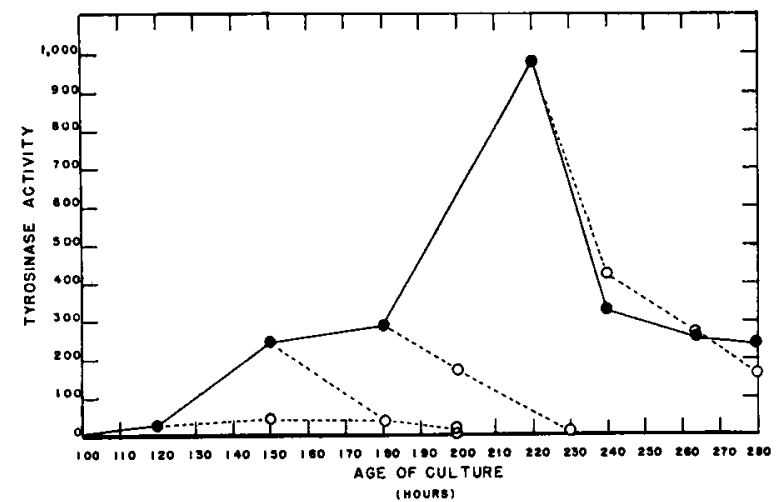

Fig. 3. Effect of incubation at $30^{\circ}$ upon tyrosinase activity in Glomerella. Solid lines connect points indicating the activity of cultures maintained at $20^{\circ}$ throughout, broken lines connect points indicating the activity of cultures moved to $30^{\circ}$ after growth at $20^{\circ}$. Tyrosinase activity is expressed as ( $\Delta$ optical density/min./mg. protein) $\times 10^{3}$.

though there are differences in the amount of growth on these sugars there is no obvious correlation with the amount of tyrosinase activity.

Discussion.-The experiments described in this paper emphasize that considerable possibility for phenotypic variation in tyrosinase activity occurs in Glomerella. Such possibilities are amply demonstrated by the data dealing with the amount of medium upon which the organism is grown. These data suggest that the concentration of nutrients is the important factor rather than the mere increase in the depth of the medium because adding double and triple the amount of medium precludes the formation of the enzyme. Therefore, it is possible that a metabolite (or metabolites) interferes with the formation of the enzyme. That the metabolite concerned is not a sulfur-containing compound of the type studied by Horowitz and Shen (1952) is suggested by the fact that no inhibitor such as was re-

TABLE 4. Tyrosinase activity in G. cingulata after growth on different carbon sources. Mycelium was grown on $25 \mathrm{ml}$. of medium for the times listed below

\begin{tabular}{lrcr}
\hline & \multicolumn{3}{c}{ Tyrosinase activity $(\Delta$ opt. } \\
& dens./min./mg. protein $\left.\times 10^{3}\right)$ & after: \\
\cline { 2 - 4 } Carbon source & $120 \mathrm{hr}$. & $180 \mathrm{hr}$. & $260 \mathrm{hr}$. \\
\hline glucose & 31 & 1215 & 1250 \\
fructose & 50 & 788 & 1205 \\
mannitol & 334 & $8500^{\mathrm{a}}$ & 4300 \\
ribose & 42 & 0 & 437 \\
xylose & 16 & 438 & 359 \\
sucrose & 3 & 39 & 182 \\
maltose & 2 & 2 & 1 \\
trehalose & 0 & 1.2 & 2 \\
\hline
\end{tabular}

a The mycelium of cultures grown in mannitol was purple black in color at this time. Mycelium grown in the other sugars was light grey or cream in color.
TABLE 5. Growth of G. cingulata on different carbon sources. Mycelium was grown on Petri dishes containing $25 \mathrm{ml}$. of medium and harvests were made at intervals. Figures are average of two samples

\begin{tabular}{|c|c|c|c|}
\hline \multirow[b]{2}{*}{ Carbon source } & \multicolumn{3}{|c|}{ Dry weight (mg.) after: } \\
\hline & $120 \mathrm{hr}$. & $180 \mathrm{hr}$. & $260 \mathrm{hr}$ \\
\hline glucose & 284 & 222 & 177 \\
\hline fructose & 294 & 236 & 197 \\
\hline mannitol & 183 & 215 & 248 \\
\hline ribose & 167 & 133 & 168 \\
\hline xylose & 346 & 218 & 189 \\
\hline sucrose & 314 & 236 & 223 \\
\hline maltose & 218 & 150 & 171 \\
\hline trehalose & 235 & 268 & 336 \\
\hline
\end{tabular}

ported by these authors has ever been found in Glomerella.

Further possibilities for phenotypic variation in the tyrosinase content of Glomerella are introduced by the effect of temperature upon enzyme formation. Although the enzyme is formed in large amounts in cultures maintained at $20^{\circ}$, none is formed at $30^{\circ}$. That this change is not inherited was demonstrated by transplantation experiments which showed the return of tyrosinase activity at $20^{\circ}$ in the first generation after colorless forms were induced at $30^{\circ}$.

An attempt was made to determine whether the enzyme itself or the enzyme-forming system is affected by the change in temperature. However, the interpretation of these data is complicated by the fact that there is an active system that is responsible for the destruction of the enzyme. In support of this assumption are previous data showing that tyrosinase activity declines rapidly after reaching its peak (Sussman and Markert, 1953). Furthermore, it is clear from the results in this paper that the processes responsible for the decrease in enzyme titer (deadaptation?) probably go on concurrently with enzyme synthesis since there is a decrease of activity at $30^{\circ}$ even before the peak is reached at $200 \mathrm{hr}$. (see fig. 3 ). That this is probably occurring at $20^{\circ}$ as well is argued for by the almost parallel decrease in the activity of the samples maintained at $20^{\circ}$ and $30^{\circ}$ after $220 \mathrm{hr}$. of growth. A possible interpretation of these data is that tyrosinase synthesis and degradation go on simultaneously after $120 \mathrm{hr}$. of growth at $20^{\circ}$. Until $220 \mathrm{hr}$., the rate of synthesis greatly exceeds that of degradation so that a net increase in activity results. However, after this time, the rate of degradation exceeds that of synthesis and a sharp decrease in titer results.

Two important differences between the tyrosinase of Glomerella and that of the related ascomycete, Neurospora, are brought into focus by these results. First, no dialyzable inhibitor such as was found by Horowitz and Shen (1952) in Neurospora has been found to occur in Glomerella. This difference 
is expressed most obviously in the color of the mycelium, for Neurospora remains uncolored while Glomerella blackens only after the onset of tyrosinase activity. The other difference concerns the question of whether the failure of these organisms to produce tyrosinase above $30^{\circ}$ is due to the thermolability of the enzyme itself or to that of the enzymeforming system. Horowitz and Fling (1953) concluded from their study of a $\mathrm{T}^{\mathrm{S}}$ (thermolabile) strain of $N$. crassa that the tyrosinase of that organ. ism is sensitive to elevated temperatures. However, the evidence obtained from the present experiments tends to rule out such a possibility in Glomerella. Thus, no significant difference in activity was found in enzyme extracts kept at 20 and $35^{\circ}$ after $2 \mathrm{hr}$. of incubation. Furthermore, when cultures which had developed tyrosinase activity at $20^{\circ}$ were moved to $30^{\circ}$, the rate at which preformed enzyme activity decreased was equivalent to that demonstrated by cultures maintained at $20^{\circ}$. It is therefore concluded that high temperatures prevent tyrosinase synthesis in Glomerella by interfering with the enzyme-forming system.

Since the kinetics of tyrosinase formation in Glomerella resemble those obtained during the induced biosynthesis of other enzymes the suggestion is that tyrosinase is adaptively formed. It is of interest to note, therefore, that high temperatures could be acting to inhibit the induced formation of tyrosinase in the manner proposed by Knox (1953) who also lists several other cases in which high temperatures act as an inhibitor. Furthermore, since the temperatures used in the present experiments inhibited the formation of tyrosinase without affecting growth there seems to be a measure of specificity involved in the effect.
That the chemical environment of the organism is important in tyrosinase formation is demonstrated by the effect of sugars. Virtually no enzyme was produced in media containing trehalose or maltose while all the other sugars tested permitted the development of tyrosinase. In this connection, it is worth noting that Boyd and Lichstein (1955) found that carbohydrates depressed tryptophanase activity in bacteria while Epps and Gale (1942) found the same to be true for bacterial deaminase and other systems. As in the present work, no correlation could be found with the amount of growth in these various media. Therefore, although the presence of carbohydrates may have a marked influence upon enzyme activity, the reasons for this are still obscure.

\section{SUMMARY}

Tyrosinase production in Glomerella is shown to be considerably affected by environmental factors like temperature, amount of medium, and carbon source. In the case of the first of these variables, considerable enzyme is produce at $20^{\circ} \mathrm{C}$. while at $30^{\circ} \mathrm{C}$. it is absent. The results suggest that the higher temperature probably affects the enzymeforming system rather than the enzyme itself. The concentration of metabolites also affects tyrosinase production since increasing amounts of the "complete" medium, or doubled and trebled amounts of the ingredients reduce or entirely preclude tyrosinase activity in agar cultures. In addition, qualitative changes in the carbon source were shown to influence enzyme production.

\footnotetext{
Department of Botany,

UNIVERSITY OF Michigan,

Ann Arbor, Michigan
}

\section{LITERATURE CITED}

Boyd, W. L., And H. C. Lichstein. 1955. The effect of carbohydrates on the tryptophanase activity of bacteria. Jour. Bact. 69: 584-589.

Eprs, H. M. R., and E. F. Gale. 1942. The influence of the presence of glucose during growth on the enzymic activities of Escherichio coli: Comparison of the effect with that produced by fermentation acids. Biochem. Jour. 36: 619-623.

Fries, LisBeth. 1953. Factors promoting growth of Coprinus fimetaria (L.) under high temperature conditions. Physiol. Plant. 6: 551-563.

Horowitz, N., and Margaret Fling. 1953. Genetic determination of tyrosinase thermostability in Neurospora. Genetics 38: 360-374.

—, AND S. Shen. 1952. Neurospora tyrosinase. Jour. Biol. Chem. 197: 513-520.

KalCKar, H. M. 1947. Differential spectrophotometry of purine compounds by means of specific enzymes. III.
Studies of the enzymes of purine metabolism. Jour. Biol. Chem. 167: 461-475.

KNox, R. 1953. The effect of temperature on enzymatic adaptation, growth, and drug resistance. pp. 184-200. In E. F. Gale and R. Davies, Ed., Adaptation in microorganisms.

Koch, L. H., And T. L. McMeekin, 1924. A new direct Nesslerization micro-kjeldahl method and a modification of the Nessler-Folin reagent for ammonia. Jour. Amer. Chem. Soc. 46: 2066-2069.

Markert, C. L. 1950. The effects of genetic changes on tyrosinase activity in Glomerella. Genetics 37: 60-75.

Ryan, E. J. 1950. Selected methods of Neurospora genetics. In R. W. Gerard, Ed., Methods in medical research. 3: $51-75$.

Sussman, A. S., and C. L. Markert. 1953. The development of tyrosinase and cytochrome oxidase activity in mutants of Glomerella cingulata. Arch. Bioch. Biophys. 45: $31-40$. 